\title{
Expression of concern: Bibliometric study of Electronic Commerce Research in Information Systems \& MIS Journals, Scientometrics, 2016, 109(3), 1455-1476 (https://doi.org/10.1007/s11192-016-2142-8)
}

\author{
Wolfgang Glänzel ${ }^{1}$
}

Published online: 11 November 2017

(C) Akadémiai Kiadó, Budapest, Hungary 2017

This Expression of Concern relates to the article entitled "Bibliometric study of electronic commerce research in information systems \& MIS Journals" by Arthur Jing Lin, ChienLung Hsu and Chun-Hao Chiang.

We are issuing this editorial expression of concern to make readers aware that concerns have been raised regarding this study. In particular, we have recently been made aware of concerns regarding consistency of data retrieval and processing, and of further inaccuracies, which compromise the replicability of the results of the study. We will investigate this issue and provide further information once it has been resolved.

This course of action follows the advice set out by Committee on Publication Ethics (COPE), of which Scientometrics is a member.

Wolfgang Glänzel

wolfgang.glanzel@kuleuven.be

1 ECOOM and Department of MSI, KU Leuven, Louvain, Belgium 